\title{
Twenty Years of donnerwheeler: What We've Learned
}

Gail J. Donner, RN (Ret'd), PhD

Partner, donnerwheeler

Mary M. Wheeler, RN, MEd, PCC

Partner, donnerwheeler

It has been 20 years since we launched donnerwheeler. Although our business began somewhat serendipitously, it has become an important part of who we are professionally and, we hope, an important part of the professional lives and careers of the thousands of nurses in Canada and abroad whom we have met along the way. As we stepped back to reflect and consider what 20 years of working together has meant, we realized that we have learned a great deal about leadership, about partnership and about entrepreneurship in nursing. Our intent in sharing these learnings with our colleagues is to begin the conversation, encourage more sharing of experiences and, overall, to contribute to advancing our understanding of what it takes to be a nursing leader.

First, some history. We never intended to go into business. We had worked together several years earlier at RNAO, and during our time there we heard from many nurses who wanted help planning their careers but had nowhere to go for a meaningful and informed career conversation. We always knew the latter was something that nursing would have to begin to do if we wanted to grow and retain the best nurses, but we didn't consider that we might be the ones who would someday play a role in making it happen.

Flash-forward to the early ' 90 s. There were still no formalized career development programs for nurses in Ontario, and we were still listening and responding to individual nurses who wanted to manage their careers more strategically but did not know how to begin the process. Gail was working at The Hospital for Sick Children (SickKids) as director of nursing education and research, Mary had begun her own consulting practice in organizational development, and health human resources was headline news. The Ontario Ministry of Health, concerned 
about nursing recruitment and retention, began the Nursing Innovation Fund, directed at providing money for innovative projects that would focus on recruiting and retaining nurses. Over lunch one day, we decided that this might be an opportunity to take our interest in career development for nurses and design an intervention that the ministry might fund. So we developed a proposal for a career planning and development program for nurses with a pre-test and post-test that looked at satisfaction and organizational commitment.

At the time, and even now, most workplace professional development programs focused on helping nurses learn what they need to do the work to be done, whereas career planning and development is helping nurses $b e$ who they want to be. We believed that if a workplace invested in its employees and provided them with arm's-length career support, those employees would stay and would be more contented in their work. Our thinking came from what we knew about Employee Assistance Programs and the principles that supported them. We enlisted the help of Janice Waddell to design the intervention with Mary, and Jean Trimnell to do the research. And we determined that SickKids would be the research site, with Gail as the principal investigator. Our proposal was rejected the first time, but after seeking help from more experienced and politically savvy colleagues, we revised the proposal and were successful in receiving a research grant.

\section{Lesson 1: Keep your dream alive!}

Dreams sustain us and keep us moving forward. Over the span of your career, you will have dreams and hopes that at times may feel unachievable. Don't give up. Timing is critical; you have to keep connected to your network and continuously scan the environment until your time and opportunity come up.

And so we began to learn about career planning and development. Having reviewed the literature, we discovered that although there was very little happening in nursing, there was some work going on in career planning generally. Working from a framework developed by Beverly Kaye (1985), we designed an intervention, Taking Control of Your Career and Your Future, that included a workshop and follow-up individual career coaching. It was fun and exciting, the research team felt good about what we were accomplishing and nurses were receptive to the offering. Our work was progressing well. Then, we started getting phone calls from nurse colleagues in other hospitals asking us to come and do "workshops or whatever you are doing at SickKids." We replied that we were doing research. After a few of those phone calls, in an inspired moment, Mary went out and bought business cards, and we launched Donner and Wheeler (our first business name). The rest is history, as the cliché goes. 


\section{Lesson 2: If you think opportunity may be behind the door, open it}

Your success rests on your adaptability and your ability to actively manage your own career. It seems to be part of the human condition that often we look at others who have had specific successes and say, "How come they got that, did that (etc.)? I could have done it." And often it is true that we could have had the same success and recognition as our colleague. What makes the difference is your openness to recognizing opportunity, your confidence in your potential, your vision for your own future and your awareness of your own strengths and limitations. This self-awareness and confidence can be developed and has to be nurtured. It is what gives us the courage to open the opportunity door.

From the very beginning, we have continued to learn, to grow and to become immersed in career planning and development, coaching and mentoring. First and foremost, we have invested in ourselves and in our partnership. We have continued to seek out education and training, and continued to develop our research and writing expertise. But it is in our partnership that some of the major lessons have been learned.

We established a few ground rules. We would talk to each other regularly and openly and not let concerns, doubts or fears stand in the way of our progress; work together as long as we found the work meaningful and were having fun, and when that stopped for either one of us, we would talk about the future of the partnership; divide the work and the profits 50-50, ensuring that each of us did the work that suited our expertise and our interests; share our work with colleagues and give them opportunities to grow and develop along with us; listen to our clients, both the organizations that retained our services and the individuals who used them, and grow and change the business to meet their needs.

\section{Lesson 3: Communicate, communicate, communicate}

Building relationships takes time and attention. It requires talking regularly and often, asking the right questions, listening to the other, clarifying goals until you are comfortable with where you are heading, taking the time to work things out together and not stopping until both are pleased with the outcome. In the right relationship, there is trust, respect, the freedom to speak truth with kindness, an acknowledgement of strengths and a climate that nurtures growth. What makes a good relationship great is the added value that comes from the pleasure each partner derives from watching the other shine and from the recognition that a partnership is so much more rewarding than two people sharing work.

Others have been very important to us in our work, helping us achieve our vision and mission. In extending our partnership to others, we have extended the scope 
and reach of our work. In addition to Janice and Jean, Chris Kebbel, Michelle Cooper and Linda McGillis Hall, among others, have walked beside us at significant times along our journey. These collaborations have allowed us to see possibilities that we had not seen and to take advantage of opportunities we didn't realize existed. They have provided clear and critical advice, shepherding our interest and commitment to helping nurses, writing, and leading important research to provide evidence for the relevance and efficacy of our collective work. They have kept us connected with "real" nurses, their goals and aspirations, as well as with trends and issues in practice and technology. We have not done it all ourselves, and not only because we couldn't, but also because we truly believe in sharing the wealth.

There are many others whom we have asked to share our work with us - for our benefit, to be sure - but also to provide them with opportunity for growth and learning. We have offered them opportunities to publish and present with us, and generally shared our passion and the fun with them. For many, the support has resulted in advancing the career of others and has also forged partnerships that have enriched and advanced the work of donnerwheeler.

\section{Lesson 4: Share your wealth, both material and social}

Share your knowledge, expertise and wisdom with others, and in turn, be open to acquiring new knowledge and different perspectives from others. When you advance others' careers, you advance yourself and the profession.

We have worked with amazing clients. From the beginning, we have worked primarily with organizations because we wanted to spread our work to as many individuals as possible, but also because we are committed to helping workplaces develop healthy work environments. We thought, and still think, that career planning and development is one way to create that environment. The clients that we have worked with have understood this, and they have taught us a lot about leadership and the realities of the workplace. We have worked together to think strategically, be clear about purpose, trust each other and be committed to achieving our mutual goals. Together with our clients, we have learned that when we have a shared vision, philosophy and values, we increase the probability of success. We can do our work just about anywhere, but it won't have an impact unless it happens in an environment that wants a culture that supports its people.

We discovered early on that spending time talking to potential clients about our work and their vision makes a huge difference in the potential success of the joint venture. If we aren't on the same page, then perhaps we aren't ready to work together.

Lesson 5: Having a shared vision with your client is critical to your mutual success It is more than clarifying outcomes and deliverables; it is about being willing and 
able to say what you hope for, what values you share and about helping each other stay true to those values and investing the time to get it right together. It's also about really "hearing" what each other is saying and being honest and responsive, even when it means you are the one that needs to change.

Twenty years ago we joined the ranks of nurse entrepreneurs, taking a dream and building a business. Entrepreneurship requires a bit of competitive spirit. That sometimes feels inconsistent with nursing values of collaboration and cooperation. But it is also what drives us to invent, to think outside the box and to push ourselves and assist other nurse leaders who also want to drive innovation and change within their workplaces. We have been doing what we love; that has been exciting for us, sometimes scary, but mostly invigorating. Nothing beats starting with a dream and only your own determination and seeing what you can build.

From a very simple beginning, we have developed a range of programs and services for nurses and for other health professionals. We have written articles and books, participated in research and spoken to anyone who would listen. We have delivered our message in Ontario, in Canada and in other parts of the world. We have worked alone, with other healthcare colleagues, with educational institutions and with nursing and healthcare organizations and associations. We have been on a mission of sorts, a mission to convince employers and leaders to consider the individual needs and potential of each of their employees and to invest in those health professionals. It is a cause that we believe in and that we have increasing evidence to support. We have never stopped learning and thinking about what could be. And that brings us to our final lesson.

\section{Lesson 6: Know your why, your purpose for being, and then be passionate about what you do - it is the key to your success!}

\section{Reference}

Kaye, B. 1985. A Guide for Career Development Practitioners: Up Is Not the Only Way. San Diego: University Associates. 